\title{
Real-time monitoring of spinal cord blood flow with a novel sensor mounted on a cerebrospinal fluid drainage catheter in an animal model
}

\author{
Yukihiro Hayatsu, MD, ${ }^{\mathrm{a}}$ Shunsuke Kawamoto, $\mathrm{MD}, \mathrm{PhD},{ }^{\mathrm{a}}$ Tadao Matsunaga, $\mathrm{PhD},{ }^{\mathrm{b}}$ \\ Yoichi Haga, $\mathrm{MD}, \mathrm{PhD},{ }^{\mathrm{c}}$ and Yoshikatsu Saiki, $\mathrm{MD}, \mathrm{PhD}^{\mathrm{a}}$
}

Objective: The aim of our study was to develop a novel monitoring system for spinal cord blood flow (SCBF) to test the efficacy of the SCBF sensor in an animal model.

\begin{abstract}
Methods: The sensor system consisted of 2 optical fibers, a pedestal for fiber fixation, and a mirror for the laser reflection and was incorporated into a cerebrospinal fluid drainage catheter. In vivo studies were performed in a swine model $(\mathrm{n}=10)$ to measure SCBF during spinal cord ischemia induced by clamping the descending thoracic aorta and supra-aortic neck vessels, when necessary. A temporary low cardiac output model was also created by inflow clamping of the inferior vena cava to analyze the quantitative changes in SCBF during this maneuver.
\end{abstract}

\begin{abstract}
Results: The developed SCBF monitoring catheter placed intrathecally could detect SCBF in all the swine. The SCBF after aortic crossclamping at the fourth intercostal level exhibited diverse changes reproducibly among the swine, with a $>25 \%$ reduction in SCBF in 5 pigs, an increase in 3, and no significant changes in 2 . Consistent reductions were recorded during inferior vena cava occlusion. The mean SCBF decreased by $32 \%$ after inferior vena cava occlusion when the cardiac output had decreased by $27 \%$.

Conclusions: We have developed a novel SCBF sensor that could detect real-time changes in spinal cord perfusion in a swine model. The device holds promise to detect imminent ischemia or ensure acceptable blood perfusion in the spinal cord and could further enhance our understanding of spinal cord circulation. ( $\mathrm{J}$ Thorac Cardiovasc Surg 2014;148:1726-31)
\end{abstract}

Thoracoabdominal aortic aneurysm (TAAA) repair carries a significant risk of spinal cord injury that will result in poor early and long-term outcomes. ${ }^{1-3}$ Although diverse strategies to prevent spinal cord injury have been used, the incidence of paraplegia and paraparesis has remained significant and has reportedly been $2.7 \%$ to $11.4 \% .^{4-7}$ The difficulty in avoiding such a devastating complication can essentially be attributed to the lack of a reliable direct monitoring system for spinal cord ischemia. The difficulties that preclude real-time monitoring of spinal cord perfusion encompass the anatomic location of the spinal cord, which is surrounded by the solid vertebral column, and the complexity of the blood supply. Thus, the development of an intraoperative continuous monitoring device for SCBF would be highly desirable.

From the Department of Cardiovascular Surgery, ${ }^{\mathrm{a}}$ Tohoku University Graduate School of Medicine, Miyagi, Japan; Micro System Integration Center, ${ }^{\mathrm{b}}$ Tohoku University, Miyagi, Japan; and Tohoku University Graduate School of Biomedical Engineering, ${ }^{\mathrm{c}}$ Miyagi, Japan.

Disclosures: Authors have nothing to disclose with regard to commercial support.

Received for publication Sept 24, 2013; revisions received March 28, 2014; accepted for publication April 4, 2014; available ahead of print May 15, 2014.

Address for reprints: Yoshikatsu Saiki, MD, PhD, Department of Cardiovascular Surgery, Tohoku University Graduate School of Medicine, 1-1, Seiryocho, Aobaku, Sendai, Miyagi 980-8574, Japan (E-mail: yoshisaiki@med.tohoku.ac.jp). $0022-5223 / \$ 36.00$

Copyright (c) 2014 by The American Association for Thoracic Surgery http://dx.doi.org/10.1016/j.jtcvs.2014.04.011
The aim of our study was to develop a novel real-time monitoring system for spinal cord blood flow (SCBF) to test the efficacy of the SCBF sensor in an animal model.

\section{METHODS}

\section{SCBF Sensor Development}

We elected to adopt the principal of laser Doppler flowmetry to put the theory into our practice. ${ }^{8,9}$ To create a novel sensor for SCBF designed for use in the intrathecal space, microelectromechanical system technology was applied.

Our SCBF sensor system consists of 2 optical fibers, a pedestal for fiber fixation, and a cerebrospinal fluid (CSF) drainage catheter (Silascon, inner diameter $0.9 \mathrm{~mm}$, outer diameter $1.65 \mathrm{~mm}$; Kaneka Medix Co, Osaka, Japan; Figure 1). The pedestal consisted of a 4-in. silicon wafer $(0.525$ $\mathrm{mm} \times 0.7 \mathrm{~mm} \times 3 \mathrm{~mm}$ ) using a dicing technique, and a mirror was attached to the tip of the pedestal for right-angled reflection of the laser. Two optical fibers were situated in 2 grooves on the upper surface of the pedestal. The sensor probe was fixed on a CSF drainage catheter using epoxide-based adhesive, and the 2 optical fibers were passed through the CSF drainage catheter and connected to a flowmeter with fiberoptic connections. With this system, the blood flow can be noninvasively monitored from an intrathecal space while simultaneously incorporating continuous CSF drainage capabilities.

\section{Ex Vivo Evaluation of SCBF Sensor}

We evaluated the SCBF sensor and compared it with a commercially available blood flow sensor (ST-N probe; Omegawave, Inc, Tokyo, Japan) in an ex vivo experiment. A noncontact blood flowmeter (FLO-N1; Omegawave, Inc, Tokyo, Japan) was chosen for this evaluation, because it is necessary to detect SCBF without coming in contact with the spinal cord 

Abbreviations and Acronyms
$\mathrm{CSF}=$ cerebrospinal fluid
IVC = inferior vena cava
MEP $=$ motor evoked potential
SCBF $=$ spinal cord blood flow
TAAA $=$ thoracoabdominal aortic aneurysm

to avoid direct tissue injury. The calibration was completed by simply pressing the button on the measurement console before usage.

In a simple evaluation, the blood flow was measured at the tip of a human subject's finger. A blood pressure cuff was placed on the humerus of the left arm, and 2 blood flow probes were set to measure the blood flow. Under stable conditions, the cuff was inflated $\leq 250 \mathrm{~mm} \mathrm{Hg}$ to interrupt the arterial blood flow of the left index finger for 30 seconds. The pressure of the cuff was then released to re-establish the blood flow. We monitored the sequential changes in blood flow 3 times in 1 person to evaluate the reliability of this SCBF sensor compared with that of the commercially available ST-N probe. In addition to blood flow, using this method, we could measure the blood volume, which represents the hemoglobin content in the tissue, and the flow velocity.

\section{In Vivo Evaluation of SCBF Sensor in a Swine Model}

We evaluated the SCBF sensor for clinical applications, in particular as a continuous blood flow-monitoring device for use in TAAA repairs. A CSF drainage catheter is routinely placed into an intrathecal space at the L4-L5 vertebral level before TAAA repair. The location of the front edge of the CSF drainage catheter is confirmed using fluoroscopy and computed tomography. However, the resolution of these modalities has not been sufficient to detect the sensor head direction because of the small sensor size $(3 \mathrm{~mm} \times 0.7 \mathrm{~mm} \times 0.525 \mathrm{~mm})$ and radiolucency of the sensor head. Therefore, the sensor head direction could be misdirected when percutaneously inserted into the intrathecal space. The determined values would be unreliable if the sensor head were not facing the spinal cord. To address this issue, we performed 3 different validations in an animal model.

In the first experiment, we evaluated the relationship between the directional characteristics of the sensor head and the intensity of the reflected signals from the SCBF. The sensor head direction was arranged under direct vision from face-to-face placement to the opposite direction gradually with the changes in the SCBF recorded.

The second experiment was designed to observe the changes in SCBF when the aorta was crossclamped at the fourth intercostal level. The supra-aortic neck vessels were also clamped when no significant changes in SCBF were observed during aortic crossclamping.

Finally, a temporary low cardiac output model was also created by inflow clamping of the inferior vena cava (IVC) to analyze the quantitative changes in SCBF during this maneuver.

\section{Animal Experiments}

Domesticated swine weighing approximately $40 \mathrm{~kg}$ were used for these experiments. The swine were fed a normal diet and received humane care in compliance with "The Guiding Principles in the Care and Use of Animals" from the Ministry of Education, Culture, Sports, Science and Technology in Japan (publication no. 71 in 2006). The animal care committee of the Tohoku University Graduate School of Medicine approved the experimental protocol (protocol no. 2013-127).

After anesthetic induction with an intramuscular injection of midazolam $(0.2 \mathrm{mg} / \mathrm{kg})$ and medetomidine $(0.05 \mathrm{mg} / \mathrm{kg})$, endotracheal intubation was performed. The swine were mechanically ventilated during the experiment. Intraoperative anesthesia was maintained with inhaled sevoflurane
(0.5\%-3.0\%) and a continuous infusion of fentanyl ( $5 \mu \mathrm{g} / \mathrm{kg} / \mathrm{h})$ and ketamine $(15 \mathrm{mg} / \mathrm{kg} / \mathrm{h})$. If the sedation was not sufficient to keep the swine stable, periodic propofol injections $(2-4 \mathrm{mg} / \mathrm{kg}$ ) were administered. The right carotid or radial arterial blood pressure, heart rate, and oxygen saturation were monitored during the procedures.

The swine was placed in a prone position, and the spinous process was exposed at the level of T9. The SCBF sensor was positioned in the intrathecal space. After repositioning in the right lateral position, an incision was made, and the descending aorta and brachiocephalic and left subclavian arteries were isolated. Finally, in a cranial direction, the SCBF sensor was inserted into the intrathecal space $\leq 5 \mathrm{~cm}$ in length at the T9 level.

\section{Directional Characteristics of SCBF Sensor}

The SCBF was measured using the SCBF sensor while changing the sensor head direction. The relationship between the spinal cord and the sensor head direction was defined as follows: face-to-face position, $0^{\circ}$; the opposite position, $180^{\circ}$; and in between, $90^{\circ}$. Additionally, the torquability of the CSF drainage catheter with 2 optical fibers was evaluated to rotate the catheter inserted through subcutaneous fat tissue $15 \mathrm{~cm}$ in length toward the spinal cord. Also, the SCBF was recorded while rotating the catheter externally to change the sensor head direction.

\section{SCBF Assessment After Aortic Crossclamping and IVC Clamping}

The SCBF was measured using the SCBF sensor after aortic crossclamping at the level of T4 and IVC clamping. The supra-aortic neck vessels were also clamped to ensure spinal cord ischemia when the SCBF did not decrease after aortic crossclamping, because significant collateral flow will be provided by the internal mammary arteries in some swine. A temporary low cardiac output model was also created by inflow occlusion using IVC clamping to analyze the quantitative changes in the SCBF during this maneuver. These maneuvers were conducted in 3 pigs to ensure reproducible observations.

\section{RESULTS}

\section{Ex Vivo Evaluation of SCBF Sensor}

The results of the ex vivo experiment are shown in Figure 2. The performance of the commercially available ST-N sensor and the new SCBF sensor was equivalent in measuring blood flow (SCBF sensor, nonischemia, $20.1 \pm$ $1.3 \mathrm{~mL} / \mathrm{min} / 100 \mathrm{~g}$ and ischemia, $1.47 \pm 0.3 \mathrm{~mL} / \mathrm{min} /$ $100 \mathrm{~g}$; ST-N sensor, nonischemia $19.9 \pm 0.6 \mathrm{~mL} / \mathrm{min} / 100$ $\mathrm{g}$ and ischemia $0.99 \pm 0.3 \mathrm{~mL} / \mathrm{min} / 100 \mathrm{~g}$ ). These results are expressed as the mean \pm standard deviation. The coefficient of correlation between these 2 sensors was 0.98 .

\section{In Vivo Evaluation of SCBF Sensor in a Swine Model} Effect of direction on SCBF sensor results. Figure 3 shows the difference in SCBF at each sensor direction (angles, $0^{\circ}, 90^{\circ}$, and $180^{\circ}$ ); the mean \pm standard deviation values are also listed in Table 1. The SCBF sensor accumulated the reflected signals more effectively at $0^{\circ}$ than at the other directions and thus detected the SCBF adequately. Furthermore, the apparent pulsatile flow, according to each heart contraction, was observed at the $0^{\circ}$ angle. However, the baseline blood flow and pulsatile flow at the $90^{\circ}$ angle were obviously decreased compared with those at $0^{\circ}$, and the SCBF sensor at $180^{\circ}$ could only detect the 


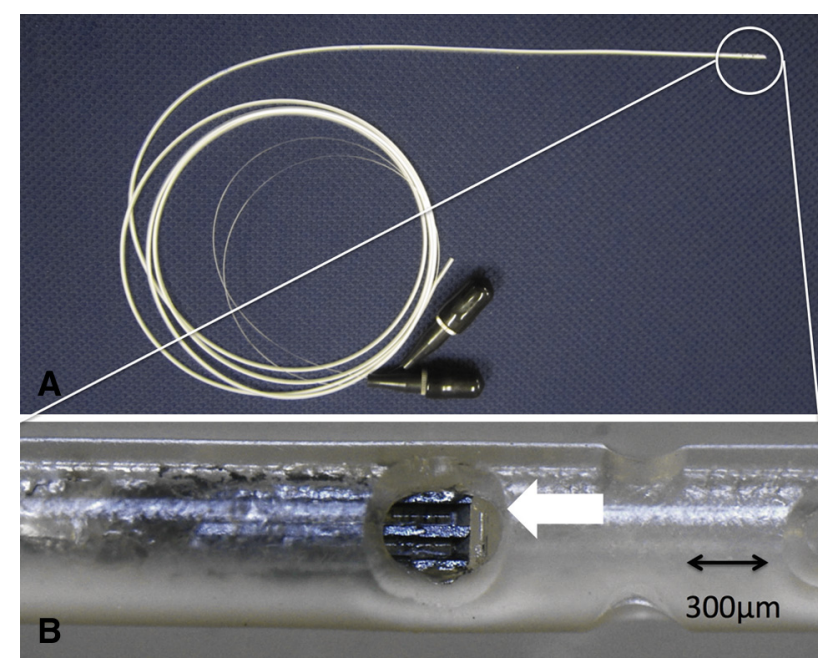

FIGURE 1. The spinal cord blood flow (SCBF) sensor combined with a cerebrospinal fluid (CSF) drainage catheter. A, Overview of the SCBF sensor combined with a CSF drainage catheter. The blood flow probe was embedded on the head of a CSF drainage catheter. Fiber cable connecters were bonded at the terminal of the optic fibers to be connected to flowmeters. B, Magnified view of the SCBF sensor on the head of a CSF drainage catheter. The side hole, $1 \mathrm{~mm}$ in diameter (solid white arrow), was punched for the laser to pass through the CSF drainage catheter.

fluctuating blood flow accompanying the respiratory movements.

Figure 4 shows the sequential changes of the recorded SCBF with the rotating SCBF sensor externally that was inserted through subcutaneous adipose tissue. The detection of the SCBF was also altered, depending on the sensor direction, and the result was the same as that when changing the sensor direction under direct vision.

SCBF variety with aortic crossclamping and IVC clamping. The SCBF changes showed 3 patterns when the descending aorta was clamped at the $\mathrm{T} 4$ level (Figure 5). These 3 patterns indicated an increase, decrease, or consistency in SCBF after the aorta was crossclamped. We defined the increase pattern as a change in blood flow $>25 \%$ of baseline, and the decrease pattern as a change in blood flow $<25 \%$ of baseline. The decrease pattern after aortic crossclamping accounted for $50 \%$ (5 of 10) of all cases, and alterations in SCBF were observed after aortic crossclamping. In the pigs whose SCBF increased after aortic crossclamping, a significant decrease in the SCBF was observed immediately after additional clamping of the neck vessels, indicating that the collateral blood supply had been interrupted by this maneuver. In addition, the reduction in cardiac output after IVC clamping induced a consistent decrease in the SCBF. Representative serial changes in SCBF, systolic blood pressure, and continuous cardiac output are shown in Figure 6; the mean values \pm standard deviation are also listed in Table 2.
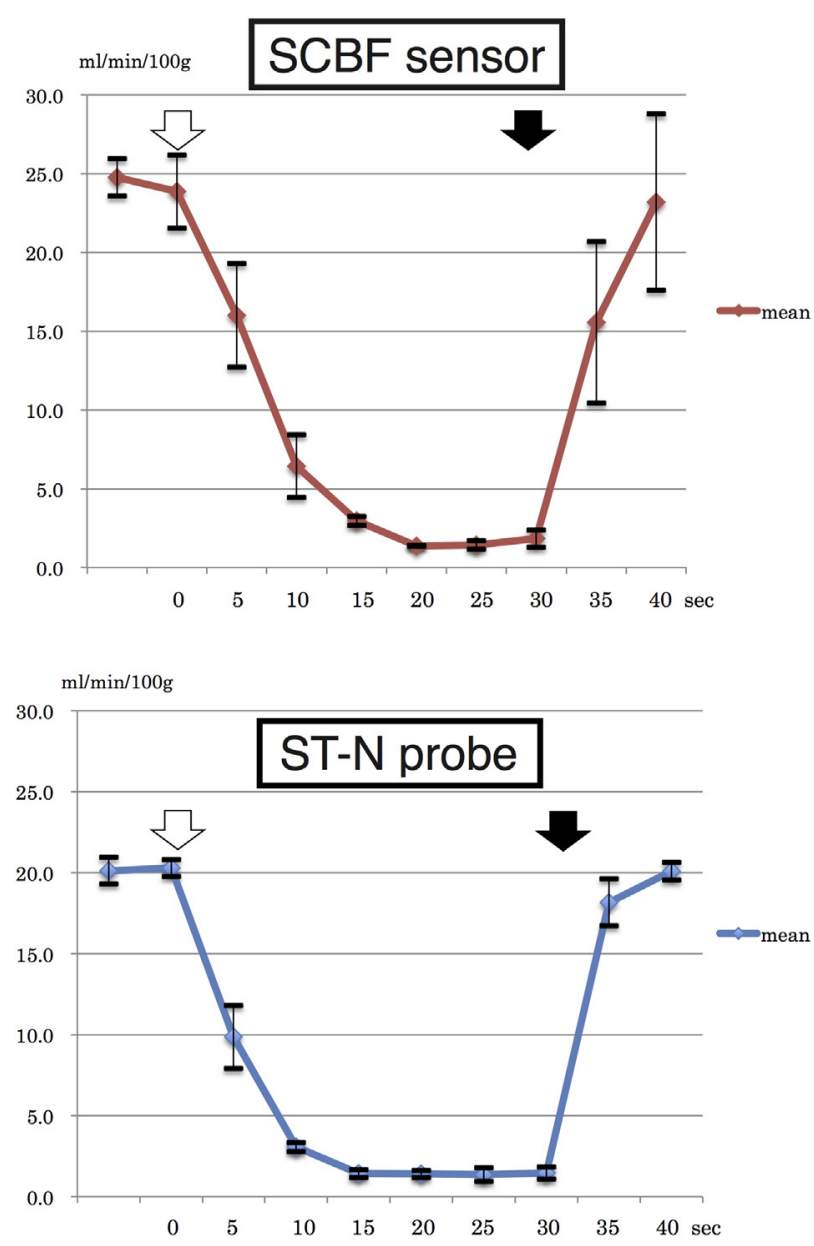

FIGURE 2. Ex vivo experiment of the index finger cutaneous blood flow measure. Sequential blood flow changes during an ischemic procedure to compress (white arrow) and decompress (black arrow) blood flow with a tourniquet. Changes were observed using 2 blood sensors (Upper, spinal cord blood flow $[S C B F]$ sensor; Lower, ST-N sensor). The values of each sensor are presented in mean \pm standard deviation. These values correlated strongly during the ischemic procedure. The coefficient of correlation was 0.98 between these 2 sensors.

\section{DISCUSSION}

Various methods have typically been applied to prevent paraplegia during TAAA repair such as CSF drainage, ${ }^{6,10,11}$ epidural cooling, ${ }^{4,12}$ intercostal artery reconstruction, ${ }^{13,14}$ and protective drug administration for the spinal cord. ${ }^{15,16}$ However, $2.7 \%$ to $11.4 \%{ }^{4-7}$ of patients still experience spinal cord injury after TAAA surgery despite these preventative measures. A long aortic crossclamp duration and the subsequent reperfusion might cause spinal cord injury, resulting in paraplegia. ${ }^{4,6,7}$ However, infrequently, patients develop paraplegia even without precipitating factors, which might represent less than sufficient spinal cord circulation. Svensson and colleagues ${ }^{17,18}$ reported on the detailed relationship between SCBF and vascular anatomy during thoracic aortic crossclamping in baboons with thoracic aortic-aortic shunts. In their studies, they 


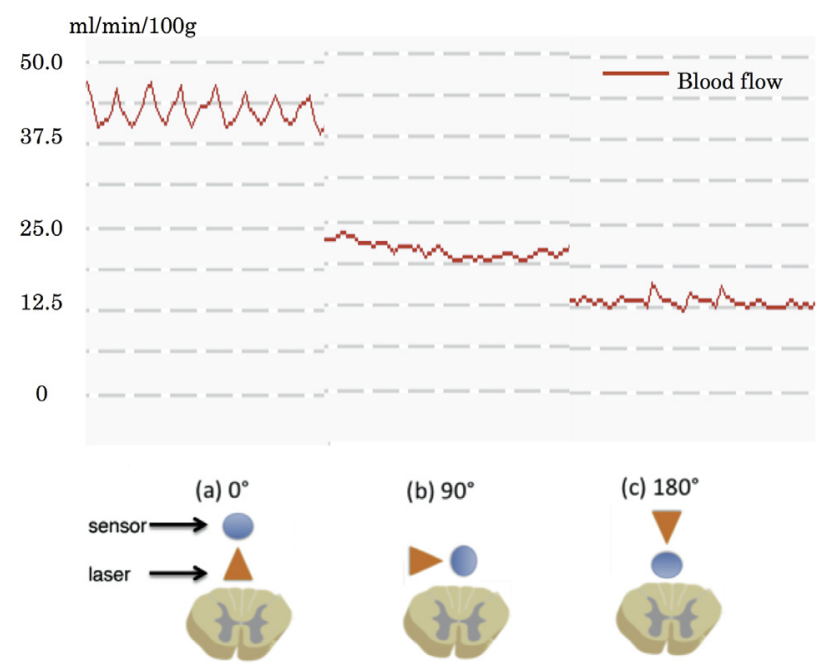

FIGURE 3. Effect of direction on the spinal cord blood flow (SCBF) sensor. Relationship between the direction of the SCBF sensor and blood flow detected. a, The SCBF sensor at $0^{\circ}$ could sufficiently detect the actual $\mathrm{SCBF}$, and the flow was obviously pulsatile. $\mathrm{b}$, The flow volume detected at $90^{\circ}$ had markedly decreased, and the pulsatile flow became less prominent. c, The detected blood flow had decreased more at $180^{\circ}$ than at $90^{\circ}$, and the fluctuated blood flow change seemed to be related to respiratory movement.

reported that distal perfusion could not increase the SCBF enough to prevent paraplegia because the caliber of anterior spinal artery became smaller above the level of the entry site of the Adamkiewicz artery.

The collateral network concept concerning spinal cord circulation, ${ }^{19-21}$ which explains that collateral flow toward the spinal cord would increase chronically after a temporary decline owing to ligation of the intercostal arteries, has recently been advocated by Griepp and Griepp. ${ }^{20}$ The aortic crossclamp would, then, not cause a critical decrease in SCBF because of the abundant collateral blood flow. However, it has been difficult to put this theory into clinical practice, and 2-staged aneurysm repair, ${ }^{22}$ thought to be an alternative method using the collateral network concept in aortic surgery, carries the risk of rupture of untreated aortic aneurysms during the waiting period before the second surgery.

We believe that the various causes of paraplegia after TAAA repair could be mitigated by continuous SCBF monitoring. Just as we have reached a consensus on the routine monitoring of the perfusion pressure or tissue saturation to confirm sufficient blood flow in selective cerebral

TABLE 1. Effect of direction on the SCBF sensor

\begin{tabular}{lc}
\hline Sensor head direction $\left(^{\circ}\right)$ & SCBF $(\mathbf{m L} / \mathbf{m i n} / \mathbf{1 0 0} \mathbf{~ g})$ \\
\hline 0 & $48.7 \pm 5.3$ \\
90 & $21.5 \pm 1.0$ \\
180 & $8.5 \pm 0.8$ \\
\hline$S C B F, S p i$
\end{tabular}

SCBF, Spinal cord blood flow.

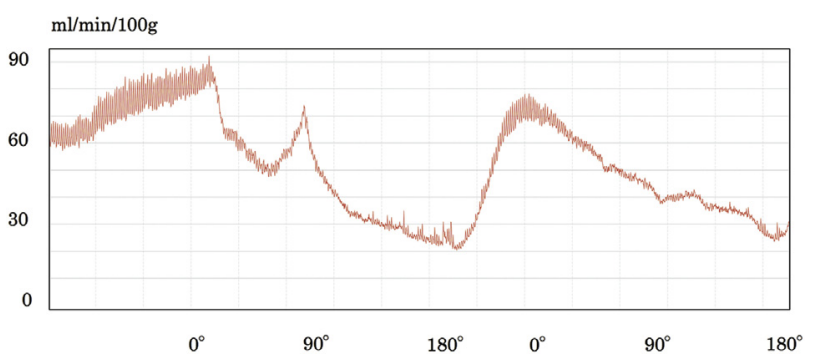

FIGURE 4. Effect of direction on the spinal cord blood flow (SCBF) sensor with external rotation. The SCBF sensor was inserted through subcutaneous adipose tissue $15 \mathrm{~cm}$ in length to evaluate its torquability for fine adjustment with external rotation. The detected SCBF was changed continuously by the rotation of the external portion of the SCBF sensor. The result in detected flow depending on the direction of the sensor was similar to the results shown in Figure 3.

perfusion or other procedures, the SCBF should also be monitored. However, this monitoring was not possible previously because of technical considerations. Evaluation of the SCBF with the SCBF sensor could be the simplest method of preventing paraplegia and could also reduce spinal cord reperfusion injury if sufficient SCBF could be determined and maintained using this sensor. Therefore, the development of a continuous monitoring device for intraoperatively monitoring SCBF has been greatly desired.

From the initial state of development, we had great concern regarding sensor reliability. We had to create a sensor that was small enough to fit through the inner lumen of a CSF drainage catheter, capable of detecting the SCBF, and with the measurement area inevitably decreasing with

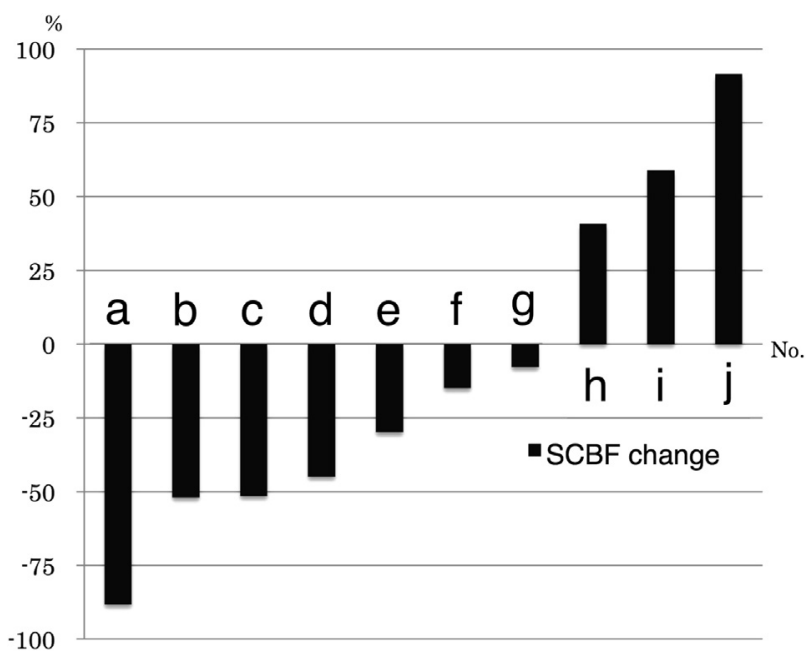

FIGURE 5. Variety of spinal cord blood flow ( $S C B F)$ changes after aortic crossclamping in the spinal cord. In this experiment, the blood flow in 10 swine was examined after aortic crossclamping. The letters on the horizontal axis (from ' $a$ ' to ' $\mathrm{j}$ ') indicate the individual pigs, and the percentage on the vertical axis indicates the ratio of blood flow change compared with that before aortic crossclamping. One half of the experimental pigs (5 of 10) experienced a decline of $>25 \%$ of the baseline blood flow. 


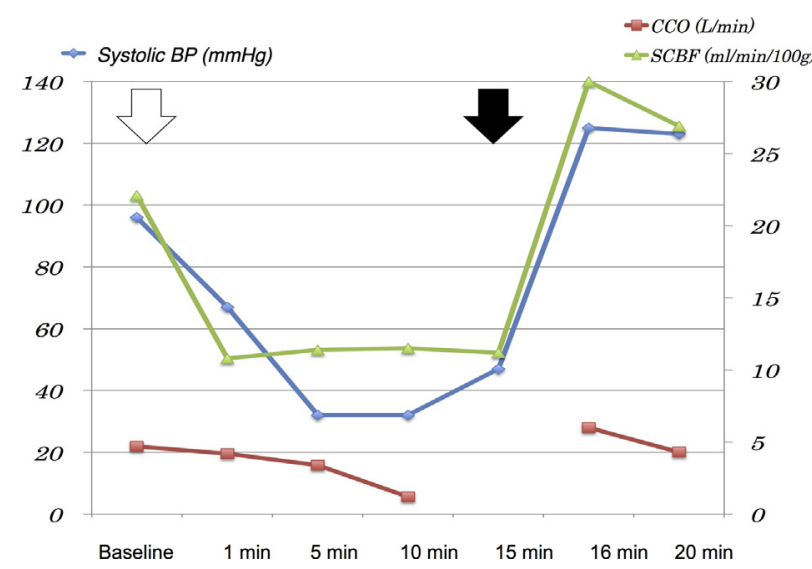

FIGURE 6. Blood flow changes after inferior vena cava (IVC) clamping. Relationship between systolic blood pressure ( $B P$, blue line), continuous cardiac output (CCO, red line), and spinal cord blood flow ( $S C B F$, green line). The change in SCBF paralleled that in the systolic BP after IVC clamping (white arrow). The decline in $\mathrm{CCO}$ was delayed by 5 minutes by the data acquisition lag, and the CCO could not be measured for $5 \mathrm{mi}-$ nutes owing to severe low cardiac output. After unclamping of the IVC (black arrow), the systolic BP and SCBF promptly increased.

the size of the sensor head. In addition to the measurement area, the intensity of the laser from the optical fibers would be attenuated by the reflection on the mirror, and a decrease in sensor sensitivity was thus considered. Another concern was the directional characteristics of the sensor. The sensor head placement direction will be completely unclear from outside the body, because it has been percutaneously inserted into the intrathecal space.

The animal experiments we performed alleviated our concerns regarding the reliability and directional characteristics of the sensor (ie, detection of pulsatile flow resolved the major issue related to the directional characteristics of the sensor). Thus, it is only necessary to rotate the SCBF sensor externally while monitoring the blood flow. When the sensor detects efficient pulsatility, the best direction for SCBF monitoring has been reached. Furthermore, the ex vivo experiments confirmed that the performance of this sensor was equivalent to that of a commercially available sensor in accuracy and quick responsiveness to blood flow changes.

Figure 5 shows the complexity of the spinal cord circulation. Bischoff and colleagues ${ }^{23}$ reported an experimental model of paraplegia after complete ligation of the segmental artery that showed that only one half of the experimental subjects developed paraplegia. Our results were similar in that $50 \%$ of the swine developed a decline in SCBF after aortic crossclamping. These 2 experiments differed in their intended observation points (ie, their experiment measured the pressure of the segmental artery and our experiment measured the direct SCBF). The segmental artery pressure will not always reflect the quantity of SCBF; however, there appears to be a strong correlation between the 2 .

Other studies have reported the utility of motor evoked potentials (MEPs) as a method of intraoperative neurologic function monitoring during TAAA surgery. ${ }^{24-27}$ Although valuable for the early detection of spinal cord ischemia, muscle relaxant drugs or hypothermia could make it difficult to judge MEP changes as real. Furthermore, continuous MEP detection would be impossible; therefore, real-time information could not be obtained from periodic MEP monitoring during TAAA repair. Thus, the SCBF sensor could be of great help for continuous monitoring of the SCBF and could also be very informative when the MEPs might have yielded a false-positive or falsenegative result. Additional comparisons between MEPs and the SCBF detected using our sensor in animal experiments could answer pending questions regarding the spinal cord circulation. Furthermore, this device could be useful in making decisions regarding intercostal arterial reconstruction during TAAA repair. For example, it might not always be necessary to reconstruct the corresponding intercostal artery in cases when temporary clamping of the intercostal arteries does not decrease the SCBF.

Thus, these devices could have complementary roles, and this promising combination for intraoperative monitoring of spinal cord perfusion might decrease the incidence of paraplegia after TAAA surgery.

\section{Study Limitations}

The present study had some limitations that we have not yet clarified for the clinical application of continuous monitoring of the SCBF. Regarding the pitfalls of sensor positioning, we believe that the appropriate position of the sensor will be in the lateral or anterior area of the spinal cord to avoid motor neuron ischemia. However, we could not determine if the position was well-suited after percutaneous insertion because we did not use a radiopaque marker.

TABLE 2. Blood flow changes after IVC clamping

\begin{tabular}{|c|c|c|c|c|c|c|c|}
\hline \multirow[b]{2}{*}{ Variable } & \multirow[b]{2}{*}{ Before IVC clamping } & \multicolumn{4}{|c|}{ IVC clamping (min) } & \multicolumn{2}{|c|}{ After declamping (min) } \\
\hline & & 1 & 5 & 10 & 15 & 1 & 5 \\
\hline $\mathrm{SCBF}(\mathrm{mL} / \mathrm{min} / 100 \mathrm{~g})$ & $22.1 \pm 8.3$ & $10.8 \pm 6.7^{*}$ & $11.4 \pm 6.7^{*}$ & $11.5 \pm 6.0^{*}$ & $11.2 \pm 5.5^{*}$ & $30.0 \pm 5.6$ & $26.9 \pm 1.4$ \\
\hline $\mathrm{SBP}(\mathrm{mm} \mathrm{Hg})$ & $96 \pm 25.5$ & $67 \pm 14.1$ & $32 \pm 5.7^{*}$ & $32 \pm 5.7^{*}$ & $47 \pm 26.9^{*}$ & $125 \pm 50.9$ & $123 \pm 26.9$ \\
\hline CCO (L/min) & $4.7 \pm 0.8$ & $4.2 \pm 0.5$ & $3.4 \pm 1.1$ & $1.2 \pm 0.1 *$ & $\dagger$ & $6.0 \pm 2.1$ & $4.3 \pm 0.6$ \\
\hline
\end{tabular}

Data presented as mean \pm standard deviation. $I V C$, Inferior vena cava; $S C B F$, spinal cord blood flow; $S B P$, systolic blood pressure; $C C O$, continuous cardiac output. *Significant difference compared with the baseline value. $† C C O$ less than the minimum value of the measurement range. 
A reduction in sensitivity for a prolonged period of use of this device is also of concern because the adhesion of proteins to the sensor probe can be presumed.

In the limitations related to the anatomic differences between swine and humans, the serial changes of SCBF after aortic crossclamping would be different depending on the development of the internal mammalian artery or other collateral pathways.

\section{CONCLUSIONS}

We have successfully developed a continuous blood flow sensor that is small enough to be mounted on a CSF drainage catheter. The sensor demonstrated prompt and accurate detection of blood flow in the spinal cord. Additional data are necessary before using the SCBF sensor for monitoring SCBF in a clinical setting. However, we strongly expect that this device will improve our understanding of spinal cord circulation and decrease the unpredictable occurrence of paraplegia during TAAA repair.

\section{References}

1. Strauss DJ, Devivo MJ, Paculdo DR, Shavelle RM. Trends in life expectancy after spinal cord injury. Arch Phys Med Rehabil. 2006;87:1079-85.

2. Middleton JW, Dayton A, Walsh J, Rutkowski SB, Leong G, Duong S. Life expectancy after spinal cord injury: a 50-year study. Spinal Cord. 2012;50: 803-11.

3. Svensson LG, Crawford ES, Hess KR, Coselli JS, Safi HJ. Experience with 1509 patients undergoing thoracoabdominal aortic operations. J Vasc Surg. 1993;17: 357-68.

4. Cambria RP, Clouse WD, Davison JK, Dunn PF, Corey M, Dorer D. Thoracoabdominal aneurysm repair: results with 337 operations performed over a 15-year interval. Ann Surg. 2002;236:471-9.

5. Estrera AL, Rubenstein FS, Miller CC III, Huynh TT, Letsou GV, Safi HJ. Descending thoracic aortic aneurysm: surgical approach and treatment using the adjuncts cerebrospinal fluid drainage and distal aortic perfusion. Ann Thorac Surg. 2001;72:481-6.

6. Coselli JS, LeMaire SA, Koksoy C, Schmittling ZC, Curling PE. Cerebrospinal fluid drainage reduces paraplegia after thoracoabdominal aortic aneurysm repair: results of a randomized clinical trial. J Vasc Surg. 2002;35:631-9.

7. Conrad MF, Crawford RS, Davison JK, Cambria RP. Thoracoabdominal aneurysm repair: a 20-year perspective. Ann Thorac Surg. 2007;83:S856-61.

8. Forrester KR, Tulip J, Leonard C, Stewart C, Bray RC. A laser speckle imaging technique for measuring tissue perfusion. IEEE Trans Biomed Eng. 2004;51: 2074-84.

9. Kashima S, Oka S, Ishikawa J, Ohsawa T, Hiki Y. Measurement of tissue blood volume in a model system and in the canine intestine by dynamic light scattering. Lasers Life Sci. 1994;6:79-90.

10. Bilal H, O'Neill B, Mahmood S, Waterworth P. Is cerebrospinal fluid drainage of benefit to neuroprotection in patients undergoing surgery on the descending thoracic aorta or thoracoabdominal aorta? Interact Cardiovasc Thorac Surg. 2012;15:702-8.
11. Lemaire SA, Price MD, Green SY, Zarda S, Coselli JS. Results of open thoracoabdominal aortic aneurysm repair. Ann Cardiothorac Surg. 2012;1:286-92.

12. Tabayashi K, Saiki Y, Kokubo H, Takahashi G, Akasaka J, Yoshida S, et al. Protection from postischemic spinal cord injury by perfusion cooling of the epidural space during most or all of a descending thoracic or thoracoabdominal aneurysm repair. Gen Thorac Cardiovasc Surg. 2010;58:228-34.

13. Svensson LG, Hess KR, Coselli JS, Safi HJ. Influence of segmental arteries, extent, and atriofemoral bypass on postoperative paraplegia after thoracoabdominal aortic operations. J Vasc Surg. 1994;20:255-62.

14. Acher CW, Wynn MM, Mell MW, Tefera G, Hoch JR. A quantitative assessment of the impact of intercostal artery reimplantation on paralysis risk in thoracoabdominal aortic aneurysm repair. Ann Surg. 2008;248:529-40.

15. Gangemi JJ, Kern JA, Ross SD, Shockey KS, Kron IL, Tribble CG. Retrograde perfusion with a sodium channel antagonist provides ischemic spinal cord protection. Ann Thorac Surg. 2000;69:1744-8.

16. Lima B, Nowicki ER, Blackstone EH, Williams SJ, Roselli EE, Sabik JF III, et al. Spinal cord protective strategies during descending and thoracoabdominal aortic aneurysm repair in the modern era: the role of intrathecal papaverine. J Thorac Cardiovasc Surg. 2012;143:945-52.

17. Svensson LG, Richards E, Coull A, Rogers G, Fimmel CJ, Hinder RA. Relationship of spinal cord blood flow to vascular anatomy during thoracic aortic crossclamping and shunting. J Thorac Cardiovasc Surg. 1986;91:71-8.

18. Svensson LG, Von Ritter CM, Groeneveld HT, Rickards ES, Hunter SJ, Robinson MF, et al. Cross-clamping of the thoracic aorta: influence of aortic shunts, laminectomy, papaverine, calcium channel blocker, allopurinol, and superoxide dismutase on spinal cord blood flow and paraplegia in baboons. Ann Surg. 1986;204:38-47.

19. Strauch JT, Spielvogel D, Lauten A, Zhang N, Shiang H, Weisz D, et al. Importance of extrasegmental vessels for spinal cord blood supply in a chronic porcine model. Eur J Cardiothorac Surg. 2003;24:817-24.

20. Griepp RB, Griepp EB. Spinal cord perfusion and protection during descending thoracic and thoracoabdominal aortic surgery: the collateral network concept. Ann Thorac Surg. 2007;83:S865-9.

21. Etz CD, Di Luozzo G, Zoli S, Lazala R, Plestis KA, Bodian CA, et al. Direct spinal cord perfusion pressure monitoring in extensive distal aortic aneurysm repair. Ann Thorac Surg. 2009;87:1764-73.

22. Etz CD, Zoli S, Mueller CS, Bodian CA, Di Luozzo G, Lazala R, et al. Staged repair significantly reduces paraplegia rate after extensive thoracoabdominal aortic aneurysm repair. J Thorac Cardiovasc Surg. 2010;139:1464-72.

23. Bischoff MS, Scheumann J, Brenner RM, Ladage D, Bodian CA, Kleinman G, et al. Staged approach prevents spinal cord injury in hybrid surgicalendovascular thoracoabdominal aortic aneurysm repair: an experimental model. Ann Thorac Surg. 2011;92:138-46.

24. Weigang E, Hartert M, Siegenthaler MP, Pitzer-Hartert K, Luehr M, Sircar R, et al. Neurophysiological monitoring during thoracoabdominal aortic endovascular stent graft implantation. Eur J Cardiothorac Surg. 2006;29:392-6.

25. Hamaishi M, Orihashi K, Takahashi S, Isaka M, Okada K, Sueda T. Transcranial motor-evoked potentials following intra-aortic cold blood infusion facilitates detection of critical supplying artery of spinal cord. Eur J Cardiothorac Surg. 2008;33:695-9.

26. Min HK, Sung K, Yang JH, Kim WS, Jun TG, Lee YT, et al. Can intraoperative motor-evoked potentials predict all the spinal cord ischemia during moderate hypothermic beating heart descending thoracic or thoraco-abdominal aortic surgery? J Card Surg. 2010;25:542-7.

27. Lancaster RT, Conrad MF, Patel VI, Cambria MR, Ergul EA, Cambria RP. Further experience with distal aortic perfusion and motor-evoked potential monitoring in the management of extent I-III thoracoabdominal aortic aneurysms. J Vasc Surg. 2013;58:283-90. 